\title{
Microbial habitability of the early Mars lacustrine environment sustained by iron redox cycling
}

\author{
Rachel A. Moore ${ }^{1, *}$ and Christopher E. Carr ${ }^{1,2}$
}

\section{Affiliations:}

${ }^{1}$ School of Earth and Atmospheric Sciences, Georgia Institute of Technology, Atlanta, GA, 30332, USA.

${ }^{2}$ Daniel Guggenheim School of Aerospace Engineering, Georgia Institute of Technology, Atlanta, GA, 30332, USA.

${ }^{*}$ Correspondence to: rmoore305@gatech.edu. Address: Weber Space Science and Technology Building, Room 210D, 275 Ferst Dr NW, Atlanta, GA 30313, USA

\section{Abstract}

Several studies have reported new data on the estimated compositions of chemical components at Gale crater; however, there is still a lack of information regarding potential past support of biomass and detectable biomarkers of ancient life. In this study we evaluate microbial habitability of early Mars constrained by the recently reconstructed water chemistry at Gale. The modeled community is based on Femetabolizing bacteria with the ability to utilize solid-phase iron oxides (e.g., magnetite) as an electron source or sink. Our results illustrate the plausibility of a sustained community in Gale Lake and provides suggestions for future modeled and laboratorybased studies to further evaluate the past habitability of Mars, biosignatures and their preservation potential, and hidden metabolic potential.

One Sentence Summary: This work provides an existence proof of habitability on early Mars and demonstrates modeling processes by which the habitability of extraterrestrial environments can be explored quantitatively.

\section{Introduction}

The modern surface of Mars is analogous to Earth's stratosphere: dry, cold, and inundated with DNA-damaging radiation. However, Mars possesses all the critical elements required for life including the essential elements (i.e., $\mathrm{C}, \mathrm{H}, \mathrm{N}, \mathrm{O}, \mathrm{P}$, and $\mathrm{S}$ ), and plausible sources of energy. It is possible that life could be present today in the Mars subsurface, beneath the cryosphere (Jones, Lineweaver and Clarke, 2011). Ancient Mars, with its higher abundance of liquid water, was arguably more hospitable to life as we know it, even while surface fluvial activity was likely transient, and temperatures generally cold (Wordsworth et al., 2021). For instance, Gale crater, a late Noachian to early Hesperian-aged crater (3.5-3.8 Gya), once harbored a liquid water lake (Grotzinger et al., 2015; Figure 1).

Recently, samples collected by the Mars Science Laboratory rover Curiosity were used to estimate Gale Lake water chemistry (Fukushi et al., 2019). Major ions $\left(\mathrm{Na}^{+}, \mathrm{K}^{+}, \mathrm{Mg}^{2+}\right.$, $\mathrm{Ca}^{2+}, \mathrm{Cl}^{-}, \mathrm{SO}_{4}{ }^{2-}, \mathrm{HCO}^{3-}$ ) and trace (e.g., $\mathrm{Zn}, \mathrm{Mg}, \mathrm{Mn}, \mathrm{Cu}, \mathrm{Fe}$ ) components were constrained, in addition to $\mathrm{pH}$ and dissolved inorganic carbon $\left(\mathrm{CO}_{2}\right)$. Taken together, 
this information provides rigorous constraints for modeling microbial habitability of Gale Lake.

Compatible microbial redox metabolisms have been suggested, however, they have yet to be experimentally assessed in an ancient Martian context (Cockell 2020). For example, several chemo-autotrophic and -heterotrophic redox couples would have been available for metabolism on the surface of Mars. Iron and sulfate ions have both been detected (Fukushi et al., 2019) and can be biologically reduced in conjunction with hydrogen. In addition, there is enough light energy and inorganic carbon to support anoxic photoautotrophy (Cockell, 2020). Phototrophy could have been productive in the "photic zone" of Gale Lake where solar energy was abundant and damaging radiation was attenuated (Cockell 2020; Figure 1 B).

This study approaches the possibility of maintaining a microbial community in Gale Lake established upon energy from light and iron redox cycling. The potential habitability of Mars and growing body of data assembled from Curiosity is the main reason for the choice of Gale crater as our study site. Our work proposes the use of Geobacter sulfurreducens and Rhodopseudomonas palustris as a simple biological community model to better understand habitability and production of detectable biomarkers in an inferred ancient lacustrine environment of Mars. Our work does not preclude other metabolisms but provides an existence proof of habitability on early Mars and a process by which habitability of extraterrestrial environments can be explored quantitatively.

\section{Materials and Methods}

\subsection{Development of genome-scale metabolic models}

Previously reconstructed and validated genome-scale metabolic models of $R$. palustris (iRpa940; Alsiyabi, Immethun and Saha, 2019) and G. sulfurreducens (iRM588; Mahadevan et al., 2006) were edited before their inclusion in community models.

Several reactions for phototrophic growth in $R$. palustris were de-simplified based on the PNSB2011 model from Hädicke, Grammel and Klamt (2011) in order to more accurately track reaction fluxes. In addition, rxn01257, which produces precursors for folate and aromatic amino acids, was added to iRpa940 after gapfilling in KBase to allow for growth in Gale Lake minimal medium (Section 2.3). The enzyme associated with this reaction (i.e., aminodeoxychorismate synthase) has been identified in other Rhodopseudomonas spp. (e.g., \#A0A1H8TD11).

The gapfilling process itself did not result in any additional added reactions to the model of $R$. palustris, however, several reaction directions were changed to be unidirectional. Three reactions were added to G. sulfurreducens (i.e., rxn05291, rxn00197, rxn00257) during gapfilling. Reactions rxn00197, rxn00257, and rxn05291 are part of the Krebs cycle which is known to be present in G. sulfurreducens (Zhang et al., 2020). In both models, reactions were expanded upon to model iron redox cycling (Supplemental file 1), which has been previously demonstrated in this specific set of two organisms (Byrne et al., 2015). Community models were created using COBRApy's merge function with objective set to sum (Supplemental file 1). Separate cytoplasmic compartments were maintained by annotation of the reactions and metabolites for each organism. The community model is represented in Figure 2 (Supplemental file 1). 
Moore and Carr

2.2 Construction of the diurnal community model

A diurnal model was constructed, based on the diuFBA model from Knies et al. 2019, using the community model of $R$. palustris and G. sulfurreducens in section 2.1 as a scaffold. Briefly, the individual metabolic models were duplicated, and a separate extracellular space was defined ("night", e2). Photon flux was only allowed in the "day" model (e0). An ATP maintenance reaction (rxn00062) was added to both organisms so that they would have to realistically expend energy even when not prioritizing growth. The reaction rates were based upon how much energy each organism spends on nongrowth-associated maintenance (Klamt, Schuster and Gilles, 2002; Mahadevan et al., 2006).

The day and night models were connected via transfer reactions that allow the "storage" and use of any metabolite, apart from photons and protons, in a different period other than when it was produced (Equation 1).

metabolite $_{i, k} \stackrel{\text { transfer }_{\longleftrightarrow}}{\longleftrightarrow}$ metabolite $_{i, k+1}$

The transfer reactions are bidirectional, as a microorganism can theoretically store metabolites from night and use them during the day, as well as store from day to use at night. This is illustrated in Figure 3.

A single biomass reaction occurs for R. palustris in "Day", and in "Night" for $G$. sulfurreducens to account for organism growth based upon when it would be prioritized (Byrne et al., 2015). Both reactions are summed to serve as the overall objective function (Fig. 3; Supplemental File 2). Flux values were integrated over 12 hours for both light and dark periods to estimate the total amount of each metabolite during one diurnal cycle (24-hour period) as in equation 2:

$\int_{0}^{12} v(t) d t=v \times \Delta t=\Delta c$

where $v$ is the flux of a given metabolite $\left(\mathrm{mmol} \mathrm{gDW}^{-1} \mathrm{~h}^{-1}\right)$, and $\Delta \mathrm{t}$ is the duration of either the light or dark period ( $12 \mathrm{~h}$ ). The result, $\Delta \mathrm{c}$, corresponds to the molar amount of a given metabolite produced in the light or dark period ( $\mathrm{mmol} \mathrm{gDW}^{-1}$; Knies et al., 2015).

\subsection{Formulation of a Gale Lake minimal medium}

An in-silico medium (Table 1) was simulated based on the methods of Marinos et al. (2020) and the composition of reconstructed water chemistry and evidence of trace minerals (Fukushi et al., 2019; Payré et al., 2019). Copper and zinc deposits within Gale crater were likely adsorbed onto Mn-oxides and thus insoluble (Payré et al., 2019). For this reason, the bounds for copper and zinc were based on the optimal rate of import from the external environment for the community model. The remaining metabolites (Table 1) were treated as soluble within the lake system. The proton flux $(\mathrm{H}+)$ reflects the neutral pH of Gale Lake proposed by Fukushi et al. (2019). Concentrations of cobalt and magnesium were calculated from the in situ Opportunity and Spirit rovers' measurements reported in Payré et al. (2019) as follows:

$\frac{P P M\left(\sim \frac{\mathrm{mg}}{\mathrm{kg}} \text { sediment }\right) \times \text { total } \mathrm{kg} \text { sediment }}{\text { total } \mathrm{kg} \text { water }}=\mathrm{mg} \mathrm{kg}^{-1}$ water 
The total mass $\left(6.67 \times 10^{6} \mathrm{~kg}\right)$ of sediment in Gale was derived from the estimated lake area $\left(2 \times 10^{10}\right.$; Fukushi et al., 2019) and the average bulk density of Martian sediment $\left(3 \times 10^{3} \mathrm{~kg} \mathrm{~m}^{-3}\right)$. Total water mass $\left(3 \times 10^{15} \mathrm{~kg}\right)$ was the lower bound estimated in Fukushi et al. (2019). The upper limit concentration of $\mathrm{N}_{2}$ was calculated using the ideal gas law, a maximum partial pressure of 0.3 bar (Von Paris et al., 2013; Navarro-Gonzalez et al 2018), a temperature of $273.15 \mathrm{~K}$ (Fukushi et al., 2019) and a Martian atmospheric mass of $2.5 \times 10^{16} \mathrm{~kg}$ (Mars Fact Sheet, 2021). The lower bound for $\mathrm{N}_{2}$ was based on the optimal rate of import from the external environment. Water was allowed to freely enter the extracellular environment at $1000 \mathrm{mmol} \mathrm{gDW}^{-1} \mathrm{~h}^{-1}$. For models with photoautotrophic growth, photons were allowed to enter the external environment at a rate of $100 \mathrm{mmol} \mathrm{gDW}^{-1} \mathrm{hr}^{-1}\left(9.7 \mu \mathrm{E} \mathrm{m}^{-2} \mathrm{~s}^{-1}\right)$.

Table 1. Estimated chemical composition of Gale Lake and corresponding bounds utilized in the modeled growth medium.

\begin{tabular}{|c|c|c|}
\hline $\begin{array}{l}\text { Metabolite / SEED } \\
\text { compound ID }\end{array}$ & $\begin{array}{l}\text { Concentration } \\
\left(\mathrm{mol} \mathrm{L}^{-1}\right)\end{array}$ & $\begin{array}{l}\text { Flux upper bound } \\
\left(\mathrm{mmol} \mathrm{gDW}^{-1} \mathrm{~h}^{-1}\right)\end{array}$ \\
\hline $\mathrm{Ca}^{2+} / \mathrm{cpd} 29674$ & $2.4-4.5 \times 10^{-2}$ * & $24-45$ \\
\hline $\mathrm{Cl}^{-} / \mathrm{cpd} 00099$ & $1.1-2.5 \times 10^{-1}$ * & $110-250$ \\
\hline $\mathrm{Co}^{2+} / \mathrm{cpd} 00149$ & $1.0-5.9 \times 10^{-6 * * * *}$ & $1.0-5.9 \times 10^{-3}$ \\
\hline $\mathrm{CO}_{2} / \mathrm{cpd} 00011$ & $2.3-41 \times 10^{-3}$ * & 2.3-41 \\
\hline $\mathrm{Cu}^{2+} / \mathrm{cpd} 00058$ & $1.0 \times 10^{-7 * * *}$ & $1.0 \times 10^{-4}$ \\
\hline $\mathrm{Fe}^{2+} / \mathrm{cpd} 10515$ & $1.2-58 \times 10^{-4}$ * & $1.2-58 \times 10^{-1}$ \\
\hline $\mathrm{H}^{+} / \mathrm{cpd} 00067$ & $1.0 \times 10^{-6 * *}$ & $1.0 \times 10^{-3}$ \\
\hline $\mathrm{H}_{2} / \mathrm{cpd} 11640$ & $1.2 \times 10^{-2} * * *$ & 12 \\
\hline $\mathrm{H}_{2} \mathrm{O} / \mathrm{cpd} 00001$ & 1.0 & 1000 \\
\hline $\mathrm{K}+/ \operatorname{cpd} 00205$ & $1.4-4.4 \times 10^{-3}$ * & $1.4-4.4$ \\
\hline $\mathrm{Mg} / \mathrm{cpd} 00254$ & $3.5-6.0 \times 10^{-2}$ * & $35-60$ \\
\hline $\mathrm{Mn}^{2+} / \mathrm{cpd} 00030$ & $5.3-100 \times 10^{-7 * * * *}$ & $5.3-100 \times 10^{-4}$ \\
\hline $\mathrm{N}_{2} / \mathrm{cpd} 00528$ & $130-220 \times 10^{-5 * \star \star \star \star *}$ & $1300-2200 \times 10^{-2}$ \\
\hline $\mathrm{Na}+/ \mathrm{cpd} 00971$ & $9.4-12 \times 10^{-2}$ * & $94-120$ \\
\hline $\mathrm{PO}_{4}^{3-} / \mathrm{cpd} 00009$ & $5.2-18000 \times 10^{-7 * * *}$ & $5.2-18000 \times 10^{-4}$ \\
\hline $\mathrm{SO}_{4}^{2-} / \mathrm{cpd} 00048$ & $4.4-7.2 \times 10^{-2}$ * & $44-72$ \\
\hline $\mathrm{Zn}^{2+} / \mathrm{cpd} 00034$ & $1.0 \times 10^{-7 * * *}$ & $1.0 \times 10^{-4}$ \\
\hline
\end{tabular}

* Data from Fukushi et al. (2019) total dissolved components of calcium, chloride, carbon dioxide, iron, hydrogen, potassium, magnesium, sodium, and sulfate, respectively.

** Calculation based on data from Fukushi et al. (2019)

*** Concentration and flux based on model requirements.

**** Calculation based on data from Lanza et al. (2014) and Berger et al. (2019)

***** Calculation based on Von Paris et al., (2013) and Navarro-Gonzalez et al (2018)

\subsection{Flux balance analysis}

The metabolic flux distribution of the individual, community, and diurnal models was calculated using flux balance analysis or dynamic flux balance analysis. The specific growth rate was used as the objective function (function to be maximized) in all simulations except for those where maximum yields of hopanoids were estimated as in Orth, Thiele and Palsson (2010). All simulations were performed using the Python programming language (version 3.8) in conjunction with open-source GLPK software 
(https://www.gnu.org/software/glpk/), and COBRApy (Ebrahim et al., 2013), pandas (Reback et al., 2020), and NumPy (Harris et al., 2020) libraries.

\section{Results}

3.1 Genome-scale metabolic models

Table 2 shows the specific growth rate for each model on the different types of substrates with or without light. Although $R$. palustris is capable of chemotrophic growth in complete media (Alsiyabi, Immethun and Saha, 2019), it fails to grow in the modeled medium without the presence of light (Table 2) or a source of organic carbon. Further, all other models grow slowly at low levels of metabolite flux in the medium $\left(0.001 \mathrm{~h}^{-1}\right.$; Table 2). At higher levels of metabolite flux, community growth is roughly two orders of magnitude faster than all other models (Table 2). For example, growth of the community in the presence of light $\left(1.031 \mathrm{~h}^{-1}\right)$ increased $\sim 2000 \%$ as compared to growth of the individual models combined (i.e., 0.005 and $0.032 \mathrm{~h}^{-1}$ or $0.037 \mathrm{~h}^{-1}$ total).

Table 2. Specific growth rates of the genome-based models under the specified conditions and constrained to either the low or high bounds of medium metabolite flux.

\begin{tabular}{lllll}
\hline $\begin{array}{l}\text { Electron } \\
\text { donor/acceptors }\end{array}$ & $\begin{array}{l}\text { Input carbon } \\
\text { source }\end{array}$ & Light? & Model & $\begin{array}{l}\text { Specific growth } \\
\text { Rate }\left(\mathbf{h}^{-1}\right)\end{array}$ \\
\hline $\mathrm{H} / \mathrm{Fe}$ & $\mathrm{CO}_{2}$ & $\mathrm{NA}$ & G. sulfurreducens & $0.001-0.005$ \\
$\mathrm{Fe} / \mathrm{CO}_{2}$ & $\mathrm{CO}_{2}$ & - & R. palustris & $0.00-0.00$ \\
$\mathrm{Fe} / \mathrm{CO}_{2}$ & $\mathrm{CO}_{2}$ & + & R. palustris & $0.001-0.032$ \\
$\mathrm{H}_{2}, \mathrm{Fe} / \mathrm{Fe}, \mathrm{CO}_{2}$ & $\mathrm{CO}_{2}$ & + & Community & $0.001-1.031$ \\
$\mathrm{H}_{2}, \mathrm{Fe} / \mathrm{Fe}, \mathrm{CO}_{2}$ & $\mathrm{CO}_{2}$ & - & Community & $0.001-1.012$ \\
\hline
\end{tabular}

NA: Not applicable

Syntrophic interactions were investigated and are presented in Table 3. Both $R$. palustris and $G$. sulfurreducens produce metabolic products consumed by the other member. For example, carbon sources (acetate and citrate) were produced and exported to the extracellular environment where "cross-feeding" can occur. Acetate produced by $G$. sulfurreducens was consumed by $R$. palustris at a rate of $86.13 \mathrm{mmol}$ $\mathrm{gDW}^{-1} \mathrm{~h}^{-1}$. Likewise, citrate was produced at a rate of $47.84 \mathrm{mmol} \mathrm{gDW}^{-1} \mathrm{~h}^{-1}$ by $R$. palustris and consumed by $\mathrm{G}$. sulfurreducens (Table 3 ). Iron $\left(\mathrm{Fe}^{2+}\right.$ and $\left.\mathrm{Fe}^{3+}\right)$ was consumed and produced at the same rate $\left(0.028-87.81 \mathrm{mmol} \mathrm{gDW}^{-1} \mathrm{~h}^{-1}\right)$ between the microbes and the extracellular environment (Table 3).

Table 3. Modeled interactions between community members*.

\begin{tabular}{lll}
\hline Metabolite & R. palustris (reaction ID) & G. sulfurreducens (reaction ID) \\
\hline Acetate & $-0.0047 /-143.5($ rxn05488) & $0.0047 / 143.5($ rxn05488) \\
$\mathrm{Fe}^{2+}$ & $0 /-0.0008($ rxn37614_2) & $0 / 0.0008($ FERCYT) \\
$\mathrm{Fe}^{3+}$ & $0 / 0.0008($ rxn37614_2) & $0 /-0.0008(\mathrm{FERCYT})$ \\
$\mathrm{Citrate}$ & $-0.0126 / 63.72($ rxn05211) & $0.0126 /-63.72($ rxn05211) \\
$\mathrm{CO}_{2}$ & $0.036 /-96.4($ rnn05467) & $-0.26 / 55.4($ rxn05467)
\end{tabular}

"Fluxes are shown in mmol gDW'- $\mathrm{h}^{-1}$ for low and high range of medium inputs with light. Negative values indicate metabolite consumption, whereas positive values indicate production.

\subsubsection{Chemolithoautotrophic metabolism of G. sulfurreducens}


Flux balance analysis revealed an unexpected hidden autotrophy, namely that $G$. sulfurreducens was capable of carbon dioxide fixation through the reverse Krebs cycle (Fig. 4). Here citrate (Table 3) was used (rxn00257) to start the cycle. $\mathrm{CO}_{2}$ was fixed at two steps, from succinyl-CoA to 2-oxoglutarate (Low-high $=0.27-43.51 \mathrm{mmol} \mathrm{gDW}^{-1} \mathrm{~h}^{-1}$; rxn00197) and from 2-oxoglutarate to isocitrate (Low-high $=0.087-30.49 \mathrm{mmol} \mathrm{gDW}^{-1}$ $\mathrm{h}^{-1} ;$ rxn00198).

\subsection{Dynamic flux balance analysis}

Dynamic growth of the community model based on nitrogen (Fig. 5), the limiting metabolite, was used to calculate the total biomass supported per $\mathrm{ml}$ of Gale Lake in the photic zone. Nitrogen was considered limiting for growth in this context as all other necessary metabolites were capable of being recycled or produced following initial input. Independent of initial media metabolite flux (i.e., High or low), 0.23 grams of biomass were produced per gram of $\mathrm{N}_{2}$ (Fig. 5). Depending on the amount of nitrogen present $\left(0.001-13 \mathrm{mmol} \mathrm{N}_{2} \mathrm{~L}^{-1}\right)$, Gale Lake could have maintained $10^{3}-10^{7}$ cells per $\mathrm{mL}$ of brine, assuming cells are $10^{-12}$ grams in weight on average (Bratbak and Dundas, 1984; see Supplemental File 4).

\subsection{Hopanoid production}

To quantify hopanoid production, the production of precursor farnesyl diphosphate was used as the objective function. Nitrogen was limited to $1 \mathrm{mmol} \mathrm{gDW}^{-1} \mathrm{~h}^{-1}$ to predict hopanoid maximum yields per mmol of limiting substrate $\left(\mathrm{N}_{2}\right)$. Farnesyl diphosphate is produced at $0.001 \mathrm{mmol}$ per mmol of $\mathrm{N}_{2}$. If, as estimated, Gale Lake contained $13 \mathrm{mmol}$ $\mathrm{N}_{2} \mathrm{~L}^{-1}$, we predict $\sim 0.01 \mathrm{mmol}$ of hopanoid was produced per liter in the photic zone. This translates to a range of $2 \times 10^{-1}-2 \times 10^{-2}$ grams of hopanoid kg ${ }^{-1}$ of Gale Crater sediment assuming a photic zone depth of $100 \mathrm{~m}$ and a sediment thickness of $1-10 \mathrm{~m}$ (see supplemental materials), assuming a preservation event (such as settling after a mass death event) of $100 \%$ of the cells and uniform mixing of settled material within the sediment.

\subsection{Diurnal community model}

The overall growth rate of the diurnal community model was roughly $2 x$ greater than the traditional community model (with light and high growth medium flux, $2.062 \mathrm{~h}^{-1}$ vs 1.031 $\left.\mathrm{h}^{-1}\right)$. In addition, G. sulfurreducens produced more biomass $\left(1.998 \mathrm{~h}^{-1}\right)$ as compared to R. palustris $\left(0.0645 \mathrm{~h}^{-1}\right)$. Overall, concentrations of metabolites (i.e., consumed and secreted) did not change significantly between periods of light and dark except for nucleic acids $\left(7.61 \times 10^{3}\right.$ vs. $\left.1.27 \times 10^{4}\right)$ and vitamins and cofactors $\left(9.74 \times 10^{3}\right.$ vs. $1.26 \times 10^{4}$ ) for R. palustris (Fig. 6 , Supplemental File 3). Transfer reaction fluxes indicated that both organisms prioritized the period in which they were growing. For instance, 5 out of the 8 metabolite categories were associated with a negative transfer flux for R. palustris indicating transfer from night to day (Fig. 7). Likewise, 6 out of the 8 categories were associated with positive flux values for $G$. sulfurreducens (Fig. 7).

\subsubsection{R. palustris transfer reaction fluxes and ATP consumption}

The nucleic acid and energy metabolite flux profiles for $R$. palustris (Fig. 7) were governed mainly by thymidine triphosphate (TTP) and guanosine triphosphate (GTP), respectively. TTP and GTP were transferred from light to dark where they served as phosphate donors to produce ATP from ADP (Fig. 7). Carbohydrates (i.e., 1,3- 
Bisphospho-D-glycerate and glycerone) were primarily transferred from night to day in R. palustris (Fig. 7). These were ultimately used to generate NADP and ATP through the production of phosphate. Inorganic ions like thiosulfate were transferred to daytime where they were used to create acetate and homocysteine, and to reduce cytochrome c3. Out of the organic acids, oxaloacetate was transferred between night and day (Fig. 7). Oxaloacetate was primarily used to power the daytime Krebs cycle.

\subsubsection{G. sulfurreducens transfer reaction fluxes and ATP consumption} Carbohydrates, inorganic ions, and organic acids were transferred at nonzero fluxes between night and day for G. sulfurreducens (Fig. 7). Of the carbohydrates, acetyl phosphate and citrate are transferred to night where they are used to make ATP. Specifically, citrate is used to power the reverse Krebs cycle (Fig. 4). The inorganic ion flux is dominated primarily by phosphate. Phosphate is transferred from night to day, where it is used to produce acetylphosphate. Acetylphosphate is used to generate ATP in both day and night. Any acetate (organic acids) produced is secreted to the extracellular space.

\section{Discussion}

In this work we evaluate the microbial habitability of early Mars' lacustrine environment constrained by reconstructed Gale Crater water chemistry and sustained by the redox cycling of iron. In this context, we used $G$. sulfurreducens and $R$. palustris as model organisms because they have been shown to effectively and anoxically use solid-phase iron oxides (Byrne et al., 2015). Although these specific organisms have been successfully co-cultured, this is not a known natural association. However, similar microbial communities have been isolated in natura. For example, an $\mathrm{Fe}(\mathrm{II})$-oxidizing photoferrotroph, Candidatus Chlorobium masyuteum, and a putative $\mathrm{Fe}$ (III)-reducing bacterium, Candidatus Pseudopelobacter ferreus, were recently co-cultured from the ferruginous Brownie Lake in Minnesota, USA (Lambrecht et al., 2021). Formate and acetate detected in Brownie Lake suggests that Fe redox cycling occurs between these two organisms, but it has not yet been confirmed. Until recently, it was thought that no one organism was capable of both $\mathrm{Fe}(\mathrm{III})$-reduction and $\mathrm{Fe}(\mathrm{II})$-oxidation. It is now understood that the bacterium Rhodoferax strain MIZ03 can utilize Fe as an electron donor and acceptor (Kato and Ohkuma, 2021).

In an evolutionary context, Alpha- and Delta-proteobacteria like R. palustris and G. sulfurreducens, respectively, probably did not arise on Earth until well after (<2-3 GYA; Marin et al., 2017; Wang and Luo, 2021) Gale crater was formed in the Late Noachian (Fig. 1C). If we assume an origin of life took place 4 GYA (i.e., either on Earth or Mars; Cantine and Fournier, 2017; Carr, 2021) and that the hypothesis of common ancestry between Earth and any possible Mars life is true (Velasco, 2018), these specific metabolisms would likely have emerged after Gale hosted a lake ( 3.8 to 3.1 GYA; Hurowitz et al., 2017). However, the modeled microorganisms are reasonable for testing early Mars habitability if we assume a second genesis occurred and/or that the timing of metabolic divergence on Mars differed from that on Earth owing to vastly different environmental conditions. 
It is important to note that a potential caveat of constraint-based modeling is that it does not account for temperature. Growth rates would be affected by changes in temperature but not growth yield. In addition, our models assumed a constant light intensity. Daily light fluctuations have been accounted for in previous models (e.g., Sarkar et al., 2019), however, this granular approach becomes exponentially complex for multi-species models and was not necessary for our assessment. Further, as $R$. palustris is a chemoautotroph and primary producer, we did not supply the models with additional carbon sources other than $\mathrm{CO}_{2}$. Organic carbon is present on Mars (Freissinet et al., 2015; Eigenbrode et al., 2018) but its distribution is not known.

In the present study, the individual models were capable of slow growth (Table 2) on the modeled medium but were predicted to grow faster together as a community, indicating syntrophy (Table 3). For instance, iron was effectively cycled by being reduced and oxidized at the same rate (Table 3). Like the findings of Byrne et al. (2015), these results indicate that iron does not become biologically unavailable to either organism unless perhaps something were to physically limit access (e.g., biofilm formation). We also found that the citrate secreted by $R$. palustris (Table 3 ) was consumed and used by G. sulfurreducens in the reverse Krebs cycle (Fig. 4), illustrating genome-scale metabolic modeling as a discovery tool. It has recently been confirmed that $G$. sulfurreducens can utilize this cycle in vitro to fix $\mathrm{CO}_{2}$ (Zhang et al., 2020). Such hidden autotrophy could also have implications for planetary protection if microbial metabolism is used to guide planetary protection requirements.

A diurnal community model was constructed to further assess cross-feeding interactions and metabolite storage during periods of light and dark (Fig. 3). Previous models have been used to illustrate the circadian growth of other microbes (e.g., cyanobacteria), but they have not been modeled in a community setting (e.g., Sarkar et al., 2019). We found that both organisms transferred metabolites to periods in which they prioritized growth (Fig. 7). For example, $R$. palustris prioritized carbohydrate use during the day to release phosphate, which is necessary to produce ATP. Additional ATP was produced at night via nucleoside-diphosphate kinases to feed the non-growth maintenance reaction. Conversely, G. sulfurreducens primarily transferred carbohydrates like citrate and acetyl phosphate to produce ATP for growth at night.

In the context of early Mars, life, if it existed there, would have likely been present in the form of a community. Microorganisms in nature are rarely found in isolation, with only one known example to date (i.e., Candidatus Desulforudis audaxviator, Chivian et al., 2008). This is because communities are better able to cope with changes in temperature, humidity, and nutrients (Palková, 2004). The syntrophic interactions identified here highlight the benefits of a community, which could allow life to adapt to varying environmental conditions just as shifts occur in our simple diurnal model. Beneficial community interactions might also have enabled life to achieve higher biomass and biosignature production than might otherwise have been possible.

Our calculations show that Gale Lake could have maintained a concentration of cells $\left(\sim 10^{3}-10^{7}\right.$ cells $\left.\mathrm{mL}^{-1}\right)$ similar to modern lakes and oceans. For example, modern terrestrial ocean waters and saltern brines have been shown to support $10^{4}-10^{6}$ cells 
per $\mathrm{mL}$ (Bar-On, Phillips and Milo, 2018; $10^{4}-10^{7}$ Klempay et al., 2021) depending on depth and other variables. Terrestrial ocean and lake sediments have also been shown to harbor $10^{4}-10^{9}$ cells per $\mathrm{cm}^{3}$ (Kallmeyer et al., 2012; Wurzbacher et al., 2017).

In addition to predicting the habitability and biomass density of early Mars, it is of particular interest to calculate the potential densities of biomarkers (i.e., molecular fossils) that could be used to detect ancient life. For example, certain membrane lipids like bacteriohopanepolyols or hopanoids can persist for billions of years in the terrestrial rock record (Brocks et al., 2005). The hopanoids synthesized by many bacteria are largely resistant to degradation because of their pentacyclic carbon skeleton, and can be detected through several analytical techniques (e.g., high-performance liquid chromatography, liquid/gas chromatography-mass spectrometry; Belin et al., 2018). Here, both R. palustris (Welander et al., 2009) and G. sulfurreducens (Härtner, Straub and Kannenberg, 2005) are known to produce biomarker hopanoids under anaerobic conditions in culture. Our model predicts that hopanoids could have been produced at a concentration $\left(\sim 10^{-1}-10^{-2} \mathrm{~g} \mathrm{~kg}^{-1}\right.$ Gale sediment; see Supplemental File 4) well above the limit of detection for miniaturized GCMS systems ( 1 PPM, Coy et al., 2011). This prediction is based on a scenario where all cells in the photic zone at some steady state timepoint settled and were evenly distributed into Gale Lake sediments and $100 \%$ preserved. While this represents an upper bound for a single such event, such events could have occurred repeatedly, due to dust storms or impact event-driven dust events blocking the sunlight required for photosynthesis. Future work could link steady state hopanoid (or other biosignature) production to deposition, preservation, and diagenesis, to yield refined estimates in support of in situ life detection.

\section{Conclusions}

Here we have demonstrated that Gale Lake could have provided the energy necessary to sustain a simple and syntrophic microbial community. It must be noted that our models and calculations contain several assumptions. For instance, Gale Lake would not have had an even distribution of light, or of any 'metabolite' for that matter, throughout its depths. It is also pertinent to note that the densities of all lake components would have changed greatly over time with evaporation (e.g., Rapin et al., 2019). This would also inevitably lead to reduction in hopanoid concentration potentially rendering it more difficult to detect. Nevertheless, these data provide guidance for Mars habitability studies. Future research should further develop and confirm candidate biosignatures in vitro and using other scenarios of habitability on early Mars and on other worlds.

\section{Acknowledgements}

The Oceans Across Space and Time team are thanked for their constructive comments.

\section{Author Disclosure Statement}

The authors declare no conflict of interest.

\section{Funding Information}

This research was financially supported by the Georgia Institute of Technology Faculty Startup funds and NASA Exobiology award 80NSSC21K1784. 
Moore and Carr

\section{References}

Alsiyabi, A., Immethun, C. M. and Saha, R. (2019) 'Modeling the Interplay between Photosynthesis, CO2 Fixation, and the Quinone Pool in a Purple Non-Sulfur Bacterium', Scientific Reports, 9(1), pp. 1-9. doi: 10.1038/s41598-019-49079-z.

Bar-On, Y. M., Phillips, R. and Milo, R. (2018) 'The biomass distribution on Earth', Proceedings of the National Academy of Sciences of the United States of America, 115(25), pp. 6506-6511. doi: 10.1073/pnas.1711842115.

Belin, B. J. et al. (2018) 'Hopanoid lipids: From membranes to plant-bacteria interactions', Nature Reviews Microbiology. Nature Publishing Group, pp. 304-315. doi: 10.1038/nrmicro.2017.173.

Berger, J. A. et al. (2019) 'Manganese enrichment pathways relevant to Gale Crater, Mars: Evaporative concentration and chlorine-induced precipitation', in 50th Lunar and Planetary Science Conference.

Borlina, C. S., Ehlmann, B. L. and Kite, E. S. (2015) 'Modeling the thermal and physical evolution of Mount Sharp's sedimentary rocks, Gale Crater, Mars: Implications for diagenesis on the MSL Curiosity rover traverse', Journal of Geophysical Research: Planets, 120(8), pp. 1396-1414. doi: 10.1002/2015JE004799.

Bratbak, G. and Dundas, I. (1984) 'Bacterial dry matter content and biomass estimations.', Applied and environmental microbiology, 48(4), pp. 755-7. Available at: http://www.ncbi.nlm.nih.gov/pubmed/6508285 (Accessed: 3 October 2018).

Brocks, J. J. et al. (2005) 'Biomarker evidence for green and purple sulphur bacteria in a stratified Palaeoproterozoic sea', Nature, 437(7060), pp. 866-870. doi: 10.1038/nature04068.

Byrne, J. M. et al. (2015) 'Redox cycling of $\mathrm{Fe}(\mathrm{II})$ and $\mathrm{Fe}(\mathrm{III})$ in magnetite by $\mathrm{Fe}$ metabolizing bacteria', Science, 347(6229), pp. 1473-1476. doi:

10.1126/science.aaa4834.

Cantine, M. D. and Fournier, G. P. (2017) 'Environmental Adaptation from the Origin of Life to the Last Universal Common Ancestor', Origins of Life and Evolution of Biospheres 2017 48:1, 48(1), pp. 35-54. doi: 10.1007/S11084-017-9542-5.

Carr, C. E. (2021) Resolving the History of Life on Earth by Seeking Life As We Know It on Mars. Atlanta.

Chivian, D. et al. (2008) 'Environmental Genomics Reveals a Single-Species Ecosystem Deep Within Earth', Science, 322(5899), pp. 275-278. doi: 10.1126/SCIENCE.1155495.

Cockell, C. (2020) Astrobiology $\square$ : understanding life in the universe. 2nd edn.

Deit, L. Le et al. (2013) 'Sequence of infilling events in Gale Crater, Mars: Results from morphology, stratigraphy, and mineralogy', Journal of Geophysical Research: Planets, 118(12), pp. 2439-2473. doi: 10.1002/2012JE004322. 
Ebrahim, A. et al. (2013) 'COBRApy: COnstraints-Based Reconstruction and Analysis for Python', BMC Systems Biology, 7(1), p. 74. doi: 10.1186/1752-0509-7-74.

Eigenbrode, J. L. et al. (2018) 'Organic matter preserved in 3-billion-year-old mudstones at Gale crater, Mars', Science, 360(6393), pp. 1096-1101. doi: 10.1126/SCIENCE.AAS9185.

Freissinet, C. et al. (2015) 'Organic molecules in the Sheepbed Mudstone, Gale Crater, Mars', Journal of Geophysical Research: Planets, 120(3), pp. 495-514. doi: 10.1002/2014JE004737.

Fukushi, K. et al. (2019) 'Semiarid climate and hyposaline lake on early Mars inferred from reconstructed water chemistry at Gale', Nature Communications, 10(1), pp. 1-11. doi: 10.1038/s41467-019-12871-6.

Grotzinger, J. P. et al. (2015) 'Deposition, exhumation, and paleoclimate of an ancient lake deposit, Gale crater, Mars', Science, 350(6257). doi: 10.1126/science.aac7575.

Hädicke, O., Grammel, H. and Klamt, S. (2011) 'Metabolic network modeling of redox balancing and biohydrogen production in purple nonsulfur bacteria', BMC Systems Biology, 5(1), pp. 1-18. doi: 10.1186/1752-0509-5-150.

Harris, C. R. et al. (2020) 'Array programming with NumPy', Nature. Nature Research, pp. 357-362. doi: 10.1038/s41586-020-2649-2.

Härtner, T., Straub, K. L. and Kannenberg, E. (2005) 'Occurrence of hopanoid lipids in anaerobic Geobacter species', FEMS Microbiology Letters, 243(1), pp. 59-64. doi: 10.1016/j.femsle.2004.11.039.

Hurowitz, J. A. et al. (2017) 'Redox stratification of an ancient lake in Gale crater, Mars', Science, 356(6341). doi: 10.1126/SCIENCE.AAH6849.

Jones, E. G., Lineweaver, C. H. and Clarke, J. D. (2011) 'An Extensive Phase Space for the Potential Martian Biosphere', Astrobiology, 11(10). doi: 10.1089/ast.2011.0660.

Kallmeyer, J. et al. (2012) 'Global distribution of microbial abundance and biomass in subseafloor sediment', Proceedings of the National Academy of Sciences of the United States of America, 109(40), pp. 16213-16216. doi: 10.1073/pnas.1203849109.

Kato, S. and Ohkuma, M. (2021) 'A Single Bacterium Capable of Oxidation and Reduction of Iron at Circumneutral pH', Microbiology Spectrum. Edited by J. A. Gralnick. doi: 10.1128/SPECTRUM.00161-21.

Klamt, S., Schuster, S. and Gilles, E. D. (2002) 'Calculability analysis in underdetermined metabolic networks illustrated by a model of the central metabolism in purple nonsulfur bacteria', Biotechnology and Bioengineering, 77(7), pp. 734-751. doi: 10.1002/BIT.10153.

Klempay, B. et al. (2021) 'Microbial diversity and activity in Southern California salterns and bitterns: analogues for remnant ocean worlds', Environmental Microbiology. doi: 10.1111/1462-2920.15440. 
Knies, D. et al. (2015) 'Modeling and simulation of optimal resource management during the diurnal cycle in Emiliania huxleyi by genome-scale reconstruction and an extended flux balance analysis approach', Metabolites, 5(4), pp. 659-676. doi: 10.3390/metabo5040659.

Lambrecht, N. et al. (2021) "'Candidatus Chlorobium masyuteum," a Novel Photoferrotrophic Green Sulfur Bacterium Enriched From a Ferruginous Meromictic Lake', Frontiers in Microbiology, 12(July), p. 1768. doi: 10.3389/FMICB.2021.695260.

Lanza, N. L. et al. (2014) 'High manganese concentrations in rocks at Gale crater, Mars', Geophysical Research Letters, 41(16), pp. 5755-5763. doi: 10.1002/2014GL060329.

Mahadevan, R. et al. (2006) 'Characterization of metabolism in the Fe(III)-reducing organism Geobacter sulfurreducens by constraint-based modeling', Applied and Environmental Microbiology, 72(2), pp. 1558-1568. doi: 10.1128/AEM.72.2.15581568.2006.

Marin, J. et al. (2017) 'The Timetree of Prokaryotes: New Insights into Their Evolution and Speciation', Molecular Biology and Evolution, 34(2), pp. 437-446. doi: 10.1093/MOLBEV/MSW245.

Marinos, G., Kaleta, C. and Waschina, S. (2020) 'Defining the nutritional input for genome-scale metabolic models: A roadmap', PLOS ONE. Edited by A. Pagnani, 15(8), p. e0236890. doi: 10.1371/journal.pone.0236890.

Mars Fact Sheet (2021) NASA. Available at: https://nssdc.gsfc.nasa.gov/planetary/factsheet/marsfact.html (Accessed: 19 August 2021).

Orth, J. D., Thiele, I. and Palsson, B. O. (2010) 'What is flux balance analysis?', Nature Biotechnology. NIH Public Access, pp. 245-248. doi: 10.1038/nbt.1614.

Palková, Z. (2004) 'Multicellular microorganisms: laboratory versus nature', EMBO Reports, 5(5), p. 470. doi: 10.1038/SJ.EMBOR.7400145.

Von Paris, P. et al. (2013) 'N2-associated surface warming on early Mars', Planetary and Space Science, 82-83, pp. 149-154. doi: 10.1016/j.pss.2013.04.009.

Payré, V. et al. (2019) 'Copper enrichments in the Kimberley formation in Gale crater, Mars: Evidence for a Cu deposit at the source', Icarus, 321, pp. 736-751. doi: 10.1016/j.icarus.2018.12.015.

Rapin, W. et al. (2019) 'An interval of high salinity in ancient Gale crater lake on Mars', Nature Geoscience, pp. 1-7. doi: 10.1038/s41561-019-0458-8.

Reback, J. et al. (2020) 'pandas'. doi: 10.5281/ZENODO.3715232.

Sarkar, D. et al. (2019) 'A diurnal flux balance model of Synechocystis sp. PCC 6803 metabolism', PLoS Computational Biology, 15(1), p. e1006692. doi:

10.1371/journal.pcbi.1006692. 
Velasco, J. (2018) 'Universal common ancestry, LUCA, and the Tree of Life: three distinct hypotheses about the evolution of life', Biology \& Philosophy 2018 33:5, 33(5), pp. 1-18. doi: 10.1007/S10539-018-9641-3.

Wang, S. and Luo, H. (2021) 'Dating Alphaproteobacteria evolution with eukaryotic fossils', Nature Communications 2021 12:1, 12(1), pp. 1-9. doi: 10.1038/s41467-02123645-4.

Welander, P. V. et al. (2009) 'Hopanoids play a role in membrane integrity and $\mathrm{pH}$ homeostasis in Rhodopseudomonas palustris TIE-1', Journal of Bacteriology, 191(19), pp. 6145-6156. doi: 10.1128/JB.00460-09.

Wordsworth, R. et al. (2021) 'A coupled model of episodic warming, oxidation and geochemical transitions on early Mars', Nature Geoscience, 14(3), pp. 127-132. doi: 10.1038/s41561-021-00701-8.

Wurzbacher, C. et al. (2017) 'Shifts among eukaryota, bacteria, and archaea define the vertical organization of a lake sediment', Microbiome, 5(1), p. 41. doi: 10.1186/S40168017-0255-9.

Zhang, T. et al. (2020) 'The hidden chemolithoautotrophic metabolism of Geobacter sulfurreducens uncovered by adaptation to formate', The ISME Journal, 14, pp. 20782089. doi: 10.1038/s41396-020-0673-8. 


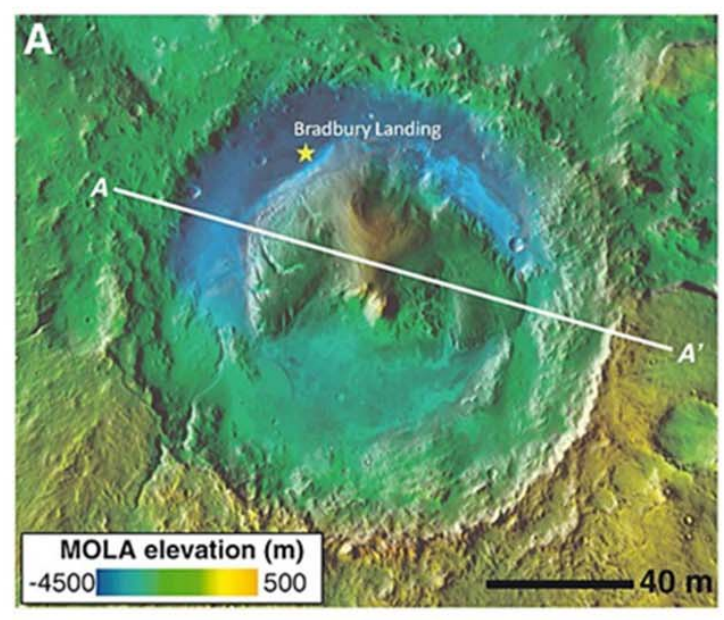

Post-impact hydrothermalism

Permafrost

Lake

Fluvial episodes

Mg-sulfate and smectite formation
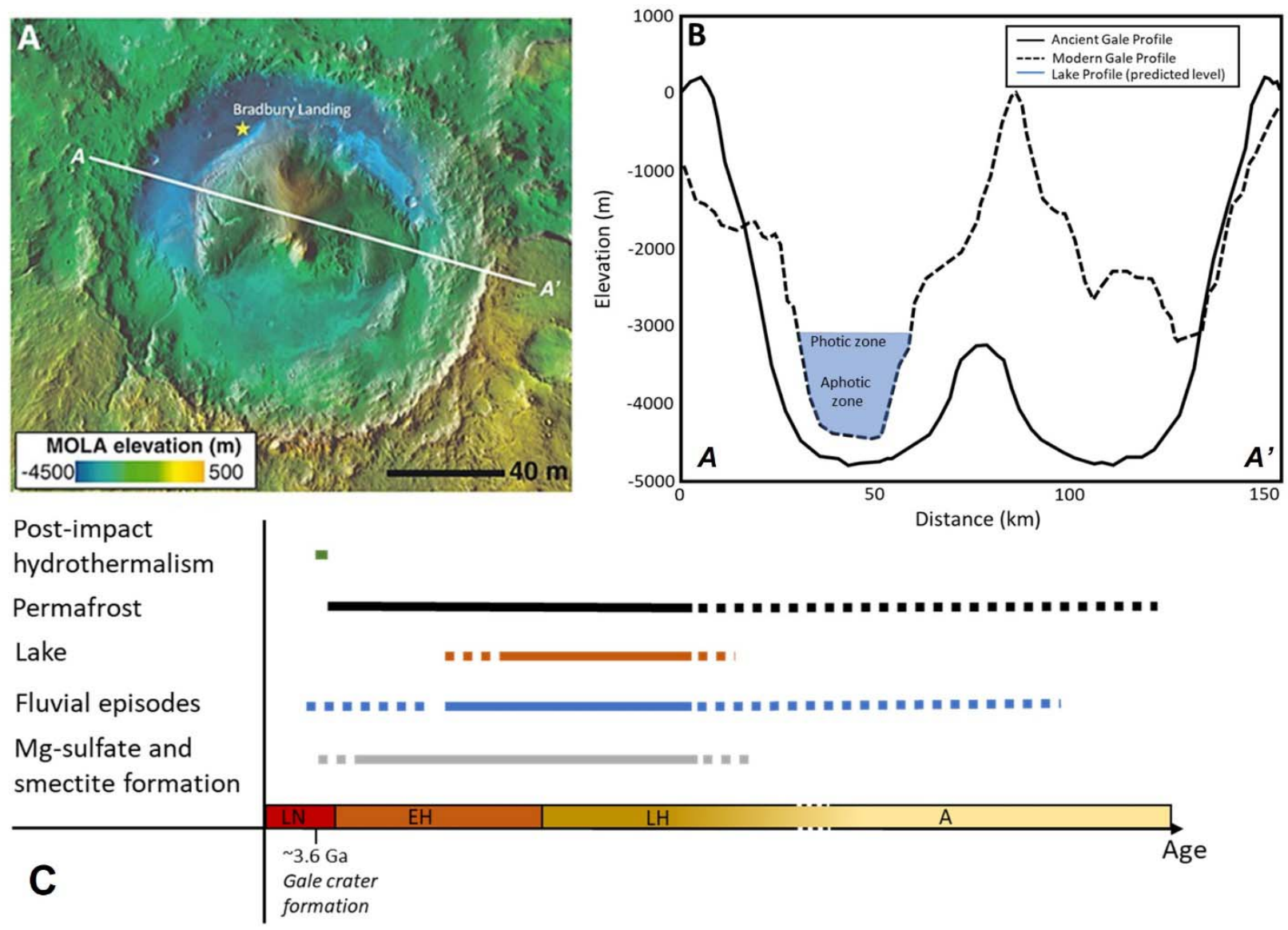

Figure 1. A. Aerial view of Gale Crater $\left(137.4^{\circ} \mathrm{E},-4.6^{\circ} \mathrm{N}\right)$ with star representing Curiosity's Bradbury landing site. B. Profiles of Gale Crater: ancient (solid line) and modern (dashed line). The water level is not to scale. Modified from Borlina, Ehlmann and Kite, 2015. C. Geologic timeline of Gale Crater starting with its formation (LN: Late Noachian, EH: Early Hesperian, LH: Late Hesperian, A: Amazonian). Modified from Deit et al., 2013. 


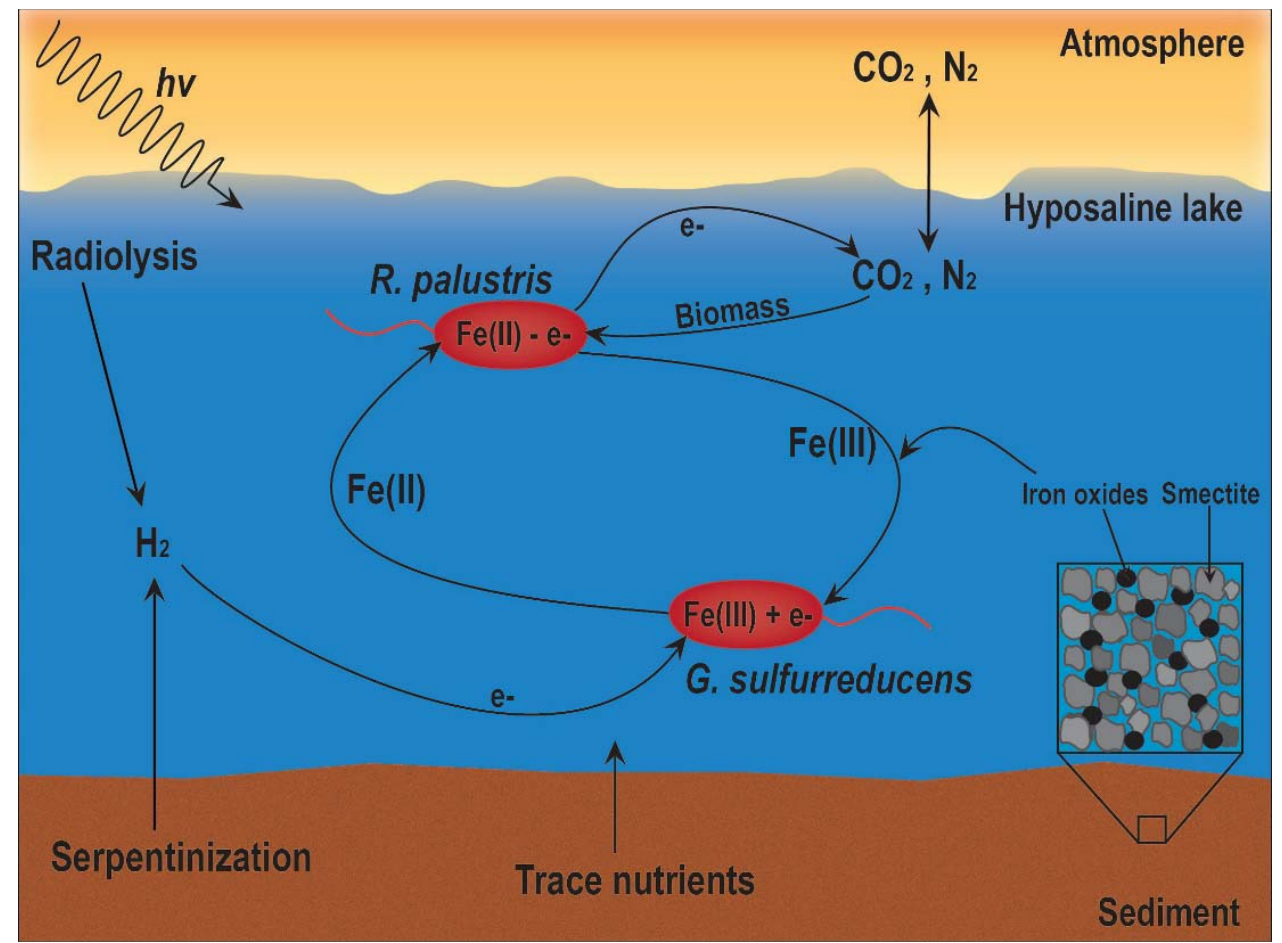

Figure 2. Model of Gale Lake emphasizing iron redox cycling phenomena.

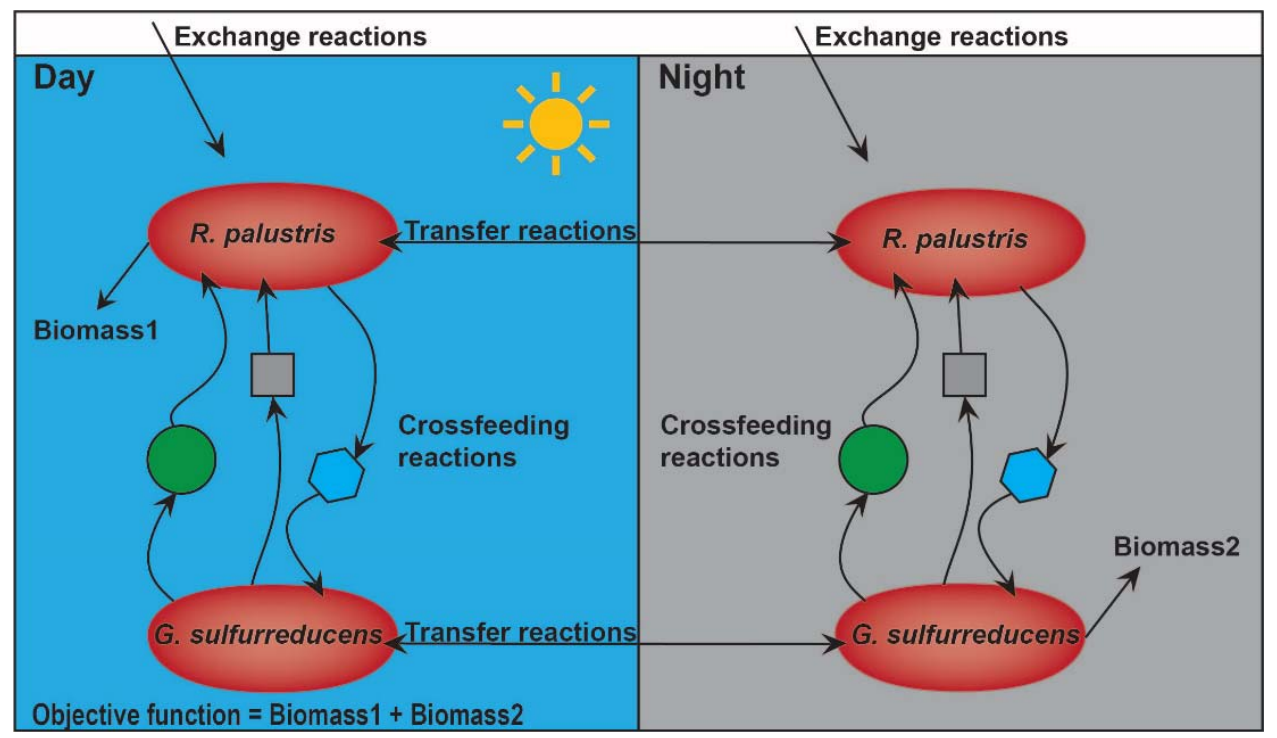

Figure 3. Schematic of the diurnal community model. 
Moore and Carr

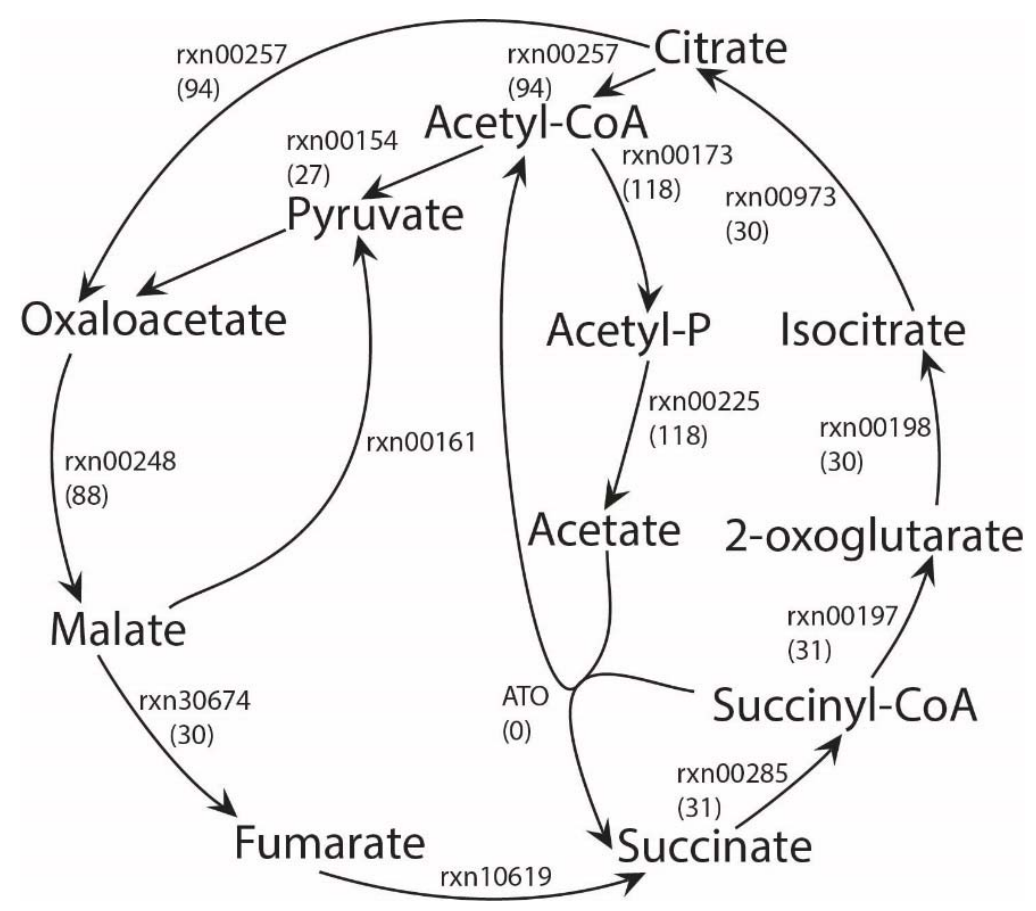

Figure 4. The reverse Krebs cycle of $G$. sulfurreducens uncovered by flux balance analysis. Numbers in parentheses refer to reaction fluxes $\left(\mathrm{mmol} \mathrm{gDW}{ }^{-1} \mathrm{~h}^{-1}\right.$, rounded to nearest whole number). The arrows refer to the direction in which each reaction is taking place.

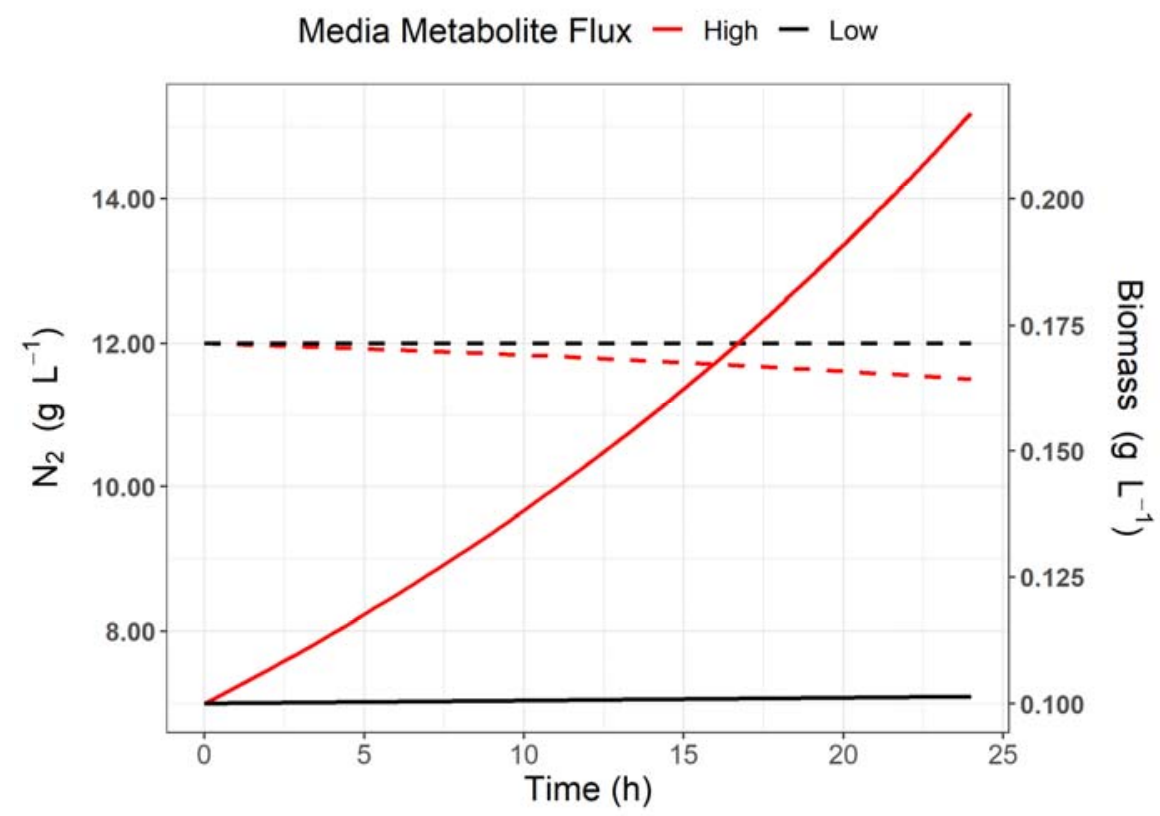

Figure 5. Production of community biomass (solid lines) and consumption of $\mathrm{N}_{2}$ (dashed lines) with low (black) or high (red) flux of metabolites in the medium. 


\section{Moore and Carr}

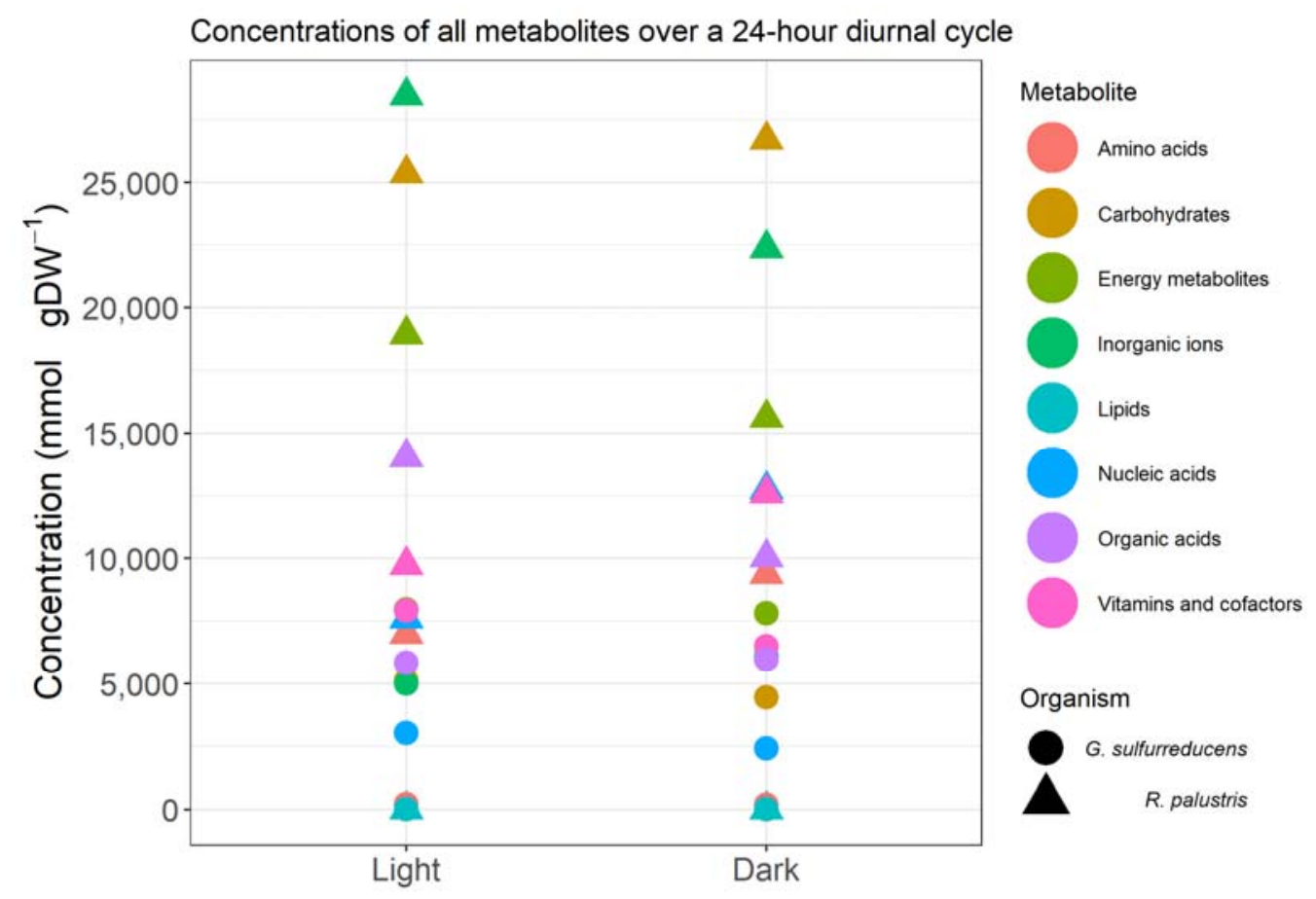

Figure 6. Metabolite concentrations summed by category for 12-hour periods of light and dark. Circles and triangles represent G. sulfurreducens and $R$. palustris, respectively

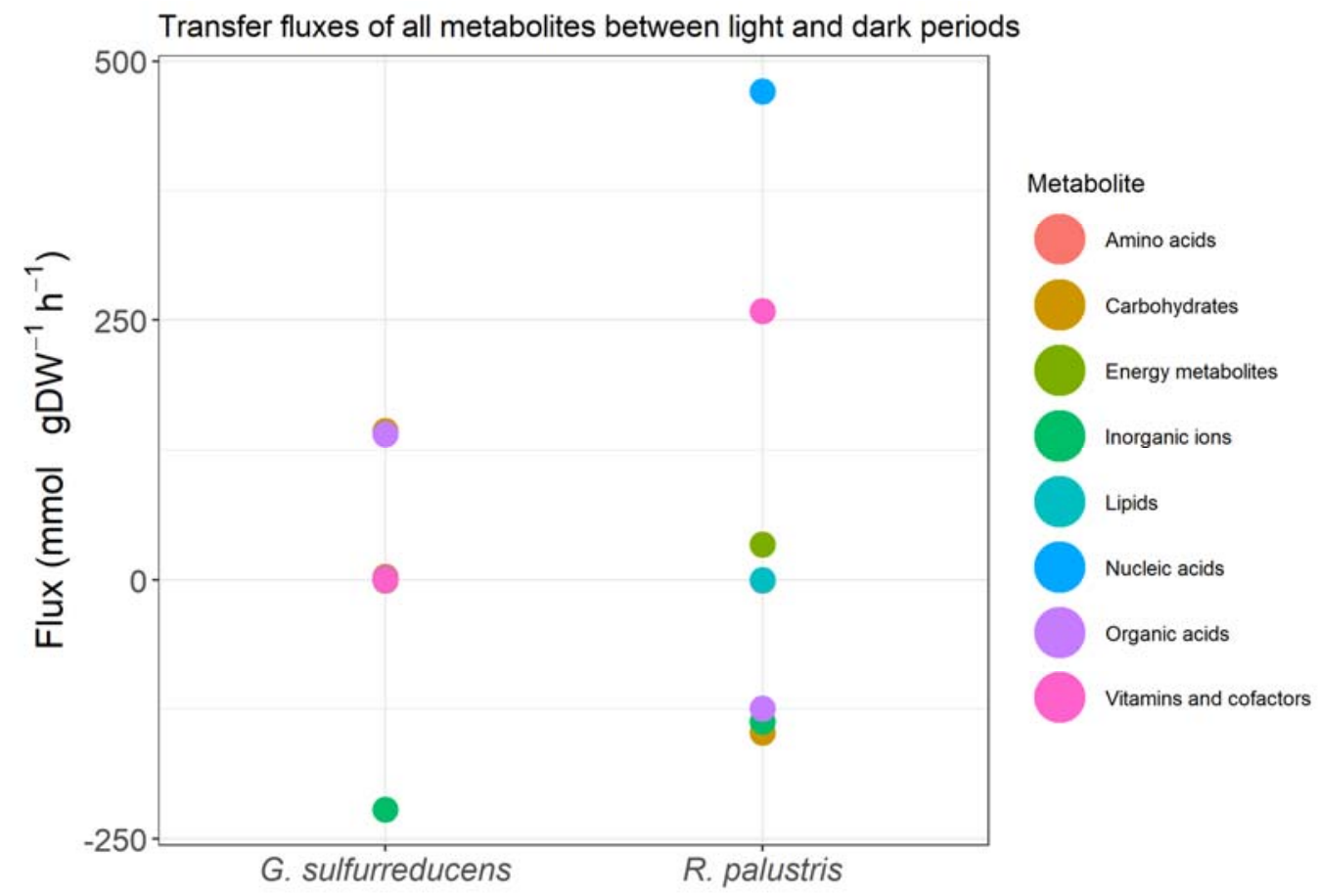

Figure 7. Metabolites transfer fluxes between light and dark summed by category. Negative values indicate transfer from night to day, and positive values indicate transfer from day to night. 
Supplemental File 1: Community model in SBML format. "c0" and "c1" indicate the cytoplasm of $R$. palustris and G. sulfurreducens, respectively.

Supplemental File 2: Diurnal community model in SBML format. " $\mathrm{c0}$ " and "c1" indicate the cytoplasm of $R$. palustris and $G$. sulfurreducens during the day, respectively, whereas "c00" and "c 11 " indicate the cytoplasm for these organisms at night.

Supplemental File 3: Outputs from the diurnal community model.

Supplemental File 4: Hopanoid calculations. 